\title{
Study of performance of h-rotor darrieus wind turbines
}

DOI:10.36909/jer.ICMMM.12441

Sandeep Christy $\mathrm{R}^{*}$, Kousik S C**, Vishal Subramaniam $\mathrm{R}^{* *}$, Santhosh Ram $\mathrm{R}^{* *}$, Nithesh Kumar R**, Gopalakrishnan $\mathrm{C}^{* *}$

* Department of Mechanical Engineering, PSG College of Technology, Coimbatore 641 004, Tamil Nadu, India.

**Department of Mechanical Engineering, PSG Institute of Technology and Applied Research, Coimbatore 641 062, Tamil Nadu, India.

**Email ID: cgk@psgitech.ac.in; Gopalakrishnan C

\begin{abstract}
Vertical Axis Wind Turbines (VAWTs) are mostly manufactured keeping in mind the site and conditions that the wind turbine would face. There is a need to know which type of VAWT would be optimal in the conditions present at the installation site. The major factors involved are blade profile, wind velocity and blade pitch angle. This study is undertaken to study these factors and their effects on influencing the efficiency of the VAWT. A model has been made of a Darrieus VAWT with H-rotor design and is analyzed using CFD. An Iso-surface mesh is made on the model with a cylindrical air-filled domain and a $\kappa-\varepsilon$ turbulence model is applied to study the effects of the wind-and-turbine blade interaction. The domain inlet indicates wind velocity; outlet is set to zero atmospheric gauge pressure and the pressure distribution across the turbine blade wall is measured. The top bottom walls of the domain are not part of the interaction. The study shows that the NACA0012 blade profile fares better than the other profiles across the range of wind velocities. However, it is less efficient with an increase in blade pitch angle for the same value of velocity. NACA0015 blade profile gives good performance when it has a zero pitch angle for intermediate and high wind velocities.
\end{abstract}


Key words: blade profile; blade pitch angle; CFD analysis; VAWT.

\section{INTRODUCTION}

The selection of the right VAWT for a particular energy requirement is critical. There are many factors to consider such as site location, wind velocity, blade profile, blade pitch angle, etc. The selection is usually done by evaluating which configuration of wind turbine has the best power coefficient i.e. absorption of wind energy. The performance analysis of the VAWT is therefore done. It is the best way to come to the conclusion of the blade profile and configuration of the turbine.

VAWTs were the first type of wind mills to be used, with an early version of the Savonius type which depended on drag force of the wind. The discovery of HAWTs and the advantageous lift force put research on the VAWT at a standstill until the advent of Darrieus wind turbines. The egg beater shape of the turbine blades was better than the Savonius blades but the HAWTs still surpassed them. Then, usage of H-rotor type Darrieus turbines gave way to increase in power coefficient among VAWTs.

Initial Darrieus straight bladed wind turbines did not have H-rotors. Their introduction gave way to the realization that the drag effect created by blades leaving limit the speed of the opposing blade, thereby propelling the whole configuration forward. This was the property of H-rotors that the starting torque was now reduced and the wind turbine can start faster than with an egg beater or non H-rotor configuration.

Studies conducted on the optimal number of blades of a VAWT indicate that there ought to be three blades attached to the turbine shaft for proper wind energy conversion. Having number of blades lower than three would decrease the swept area and hence, the power coefficient would also decrease. Having more than three blades would obstruct the wind from flowing through the turbine; at higher speeds, it could potentially cause the main turbine body to act as 
a solid cylinder in fluid flow and obstruct the wind from flowing through the turbine. The design of the wind turbine is a tested model of a standard H-rotor Darrieus wind turbine. The appropriate airfoil blade profiles to be used for the analysis are NACA0012, NACA0015, NACA0018, NACA4415 and the like. These profiles have been arrived at for usage in wind turbine applications by extensive studies conducted.

\section{LITERATURE REVIEW}

\section{Types of Wind Turbines:}

There are two basic designs of wind turbines: Horizontal Axis Wind Turbines (HAWTs) and VAWTs. HAWTs contain blades which are attached perpendicular to axis shaft. In this type of turbine, the main rotor shaft is set vertically and the main components are located at the base of the turbine. It provides enough power but still has lesser advantages than a VAWT. VAWTs are a type of wind turbine where the main rotor shaft is set traverse, not necessarily vertical, to the wind and the main components are located at the base of the turbine. This arrangement allows the generator and gearbox to be located close to the ground, facilitating service and repair. VAWTs do not need to be pointed into the wind, which removes the need for wind-sensing and orientation mechanisms. Vertical axis wind turbines can further be classified into two types: (i) Darrieus type and (ii) Savonius type. Darrieus type rotor wind mill needs much less surface area than Savonius type. These turbines are powered by wind coming from all directions. Due to its versatility, vertical axis wind turbines are thought to be ideal for installations where wind conditions are not consistent.

Types of Rotor Configuration of VAWTs:

\section{Egg-beater configuration}

The egg beater has symmetrical airfoil blades which move in a circular path the top and bottom of the blade attached to the central shaft. The starting torque of this configuration was 
very high and therefore required higher wind velocity to get running smoothly. The stability of the turbine required proper stability of the central shaft.

\section{H-rotor configuration:}

The H-rotor or Giromill configuration has straight vertical airfoil blades which are attached to the central shaft by horizontal supports. The vertical blades replace the long egg beater blades of the original Darrieus design.

The introduction of the H-rotor configuration brought about hopes of making a VAWT that would in theory, catch up to and maybe, overcome the output generation of HAWTs. The use of airfoil profile blades in Darrieus H-rotor turbines provided a better energy transfer than all other VAWT types.

\section{Parameters in the Design of Wind Turbine:}

Betz Limit: High rotor efficiency is desirable for increased wind energy extraction. A physical limit, independent of design, exists for the quantity of energy that can be extracted from wind. The magnitude of energy harnessed correlates to reduction in wind speed over the turbine. $100 \%$ extraction implies zero final velocity, meaning zero flow of wind beyond the turbine. This scenario is impossible. Studies conducted indicate that wind turbine efficiency cannot exceed $59.3 \%$. This parameter, commonly known as the power coefficient $\left(\mathrm{c}_{\mathrm{p}}\right)$, where $\max c_{p}=0.593$, also referred to as the Betz limit. Constant linear velocity is assumed. Therefore, forces like wake rotation, drag or vortex turbulence further reduces maximum efficiency.

Keeping the limitations imposed by the Betz limit in mind, the parameters involved in wind turbine design are: -

Airfoil: Any airfoil shaped bodies are known to produce an aerodynamic force when moved through a fluid. The force component perpendicular to direction of motion is called lift and 
the one parallel to the direction of motion is called drag. Subsonic airfoils, such as those used in a wind turbine, have a rounded leading edge and a sharp trailing edge, with the upper and lower surfaces being symmetric. Airfoils (Fig.6) are used in aircraft, helicopters, propellers, fans, turbines and compressors.

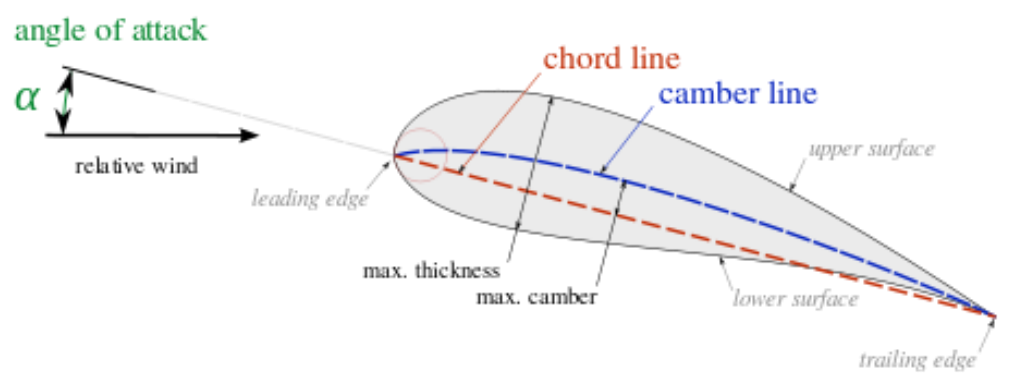

Figure 1 Parts of an airfoil blade (Source: Wikipedia)

NACA Airfoils are airfoil shapes developed by the National Advisory Committee for Aeronautics, a U.S. Federal agency for aeronautical research. Each NACA airfoil shape is designated by a four-digit number. The digits of the number designate the airfoil shape. The first digit gives the maximum camber as percentage of the chord of the airfoil. The second digit gives the distance of maximum camber from the leading edge of the airfoil in tens of percent of the chord. The last two digits indicate the maximum thickness of the airfoil as percent of the chord. For example, the NACA 4412 airfoil has a maximum camber of $4 \%$ located at $40 \%$ of chord length from the leading edge with a maximum thickness of $12 \%$ of the chord.

Research has been done to find out which airfoil profile would provide the best results for use in VAWTs with profiles like NACA0012, NACA0015, NACA0018, NACA0021, NACA4415 giving the best results of the lot.

Blade Pitch Angle: The blade pitch angle (or angle of attack) of the wind relative to the blade has also been found to be influential in the wind turbine design. The blade pitch angle is the angle between the line of chord of airfoil and the relative airflow. The lift coefficient of a 
turbine blade depends on the blade pitch angle. A higher lift coefficient provides a better power coefficient. Blade pitch angles normally set range from $-5^{\circ}$ up to $15^{\circ}$. This angle can be changed by means of control mechanisms in order to control the production and absorption of power. Blade pitch control is essential for all turbines, horizontal and vertical. The pitch is adjusted to keep the rotor speed within operating limits in accordance with the wind speed. The blade pitch angle plays a role in determining the amount of blade area that is exposed to the wind coming in.

Wind velocity: The wind power density is the number of watts of electrical energy produced per square meter of air space $\left(\mathrm{W} / \mathrm{m}^{2}\right)$. This value is normally given at $10 \mathrm{~m}$ or $50 \mathrm{~m}$ above the ground. In general, the available wind generation capacity is determined by the average wind speed over the year for each location. These data about wind speeds are useful in determining the size and siting of the wind turbine. At low speeds $(0-2 \mathrm{~m} / \mathrm{s})$, wind turbines are expected to have a low power output as the power generated is directly related to the rotational speed of the turbine. At high stormy speeds $(>15 \mathrm{~m} / \mathrm{s})$, there exists a risk of structural failure of the turbine due to high wind forces. Therefore, it is usually recommended to operate wind turbines at intermediate wind speeds $(3-12 \mathrm{~m} / \mathrm{s})$. This range of speeds is based on the average wind speeds available around the world. The H-rotor Darrieus VAWT is first modeled and then performance analysis is done using ANSYS software. Four different airfoils set at three different blade pitch angles are tested for maximum power coefficient at three different wind speed velocities.

\section{Modeling of straight-bladed VAWT}

In this study, small H-rotor Darrieus VAWT which is the most popular in domestic and foreign power generation communities as a viable VAWT is studied as the research object. Blades of VAWT are made of uniform section and non-twisted. Modeling software 
SolidWorks is used in modeling the turbines. The dimensions are shown in Fig.2 and Fig.3, while the complete model is shown in Fig.4.

Dimensions of the wind turbine:

Blade chord length $=267.43 \mathrm{~mm}($ Fig.2)

Swept Diameter $=\mathrm{D}=2000 \mathrm{~mm}$

Number of blades $=3$

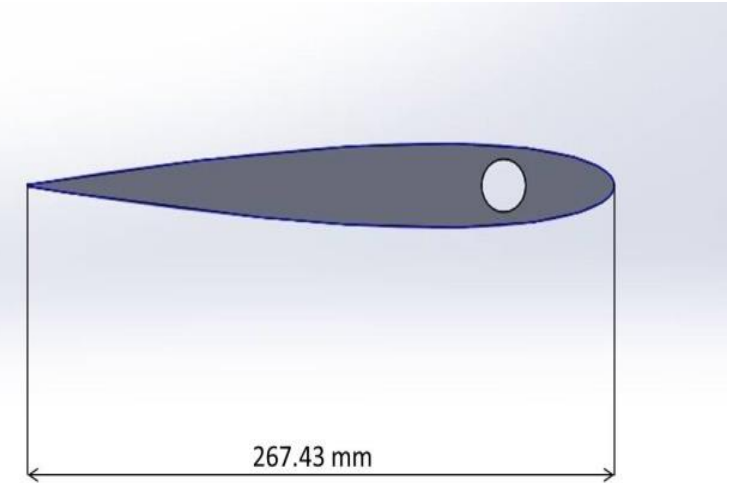

Blade height $=\mathrm{H}=1200 \mathrm{~mm}$ (Fig.3)

Figure 2 Top view of blade

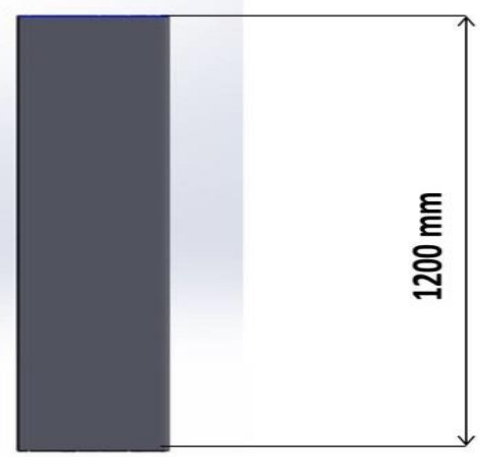

Figure 3 Front view of blade



Figure 4 Complete view of wind turbine model

The airfoil profiles used in this study are NACA0012, NACA0015, NACA0018 and NACA0021. The blade pitch angles for which this study is conducted are $0^{\circ}, 2^{\circ},-2^{\circ}$. Twelve models are made of the wind turbine. 
The blade profiles are represented below:
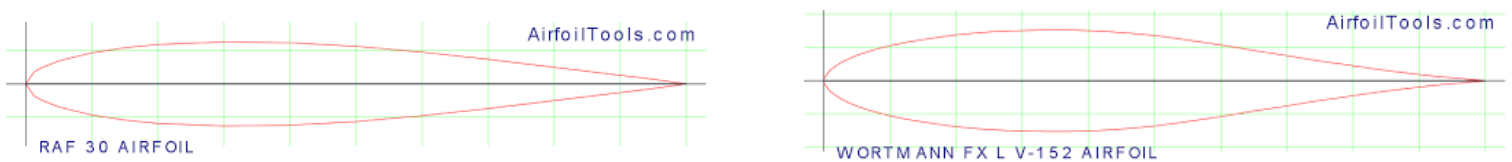

(Figs.5(a)-5(d))

(a) NACA0012

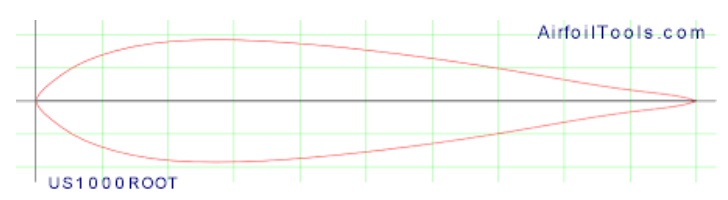

(b) NACA0015

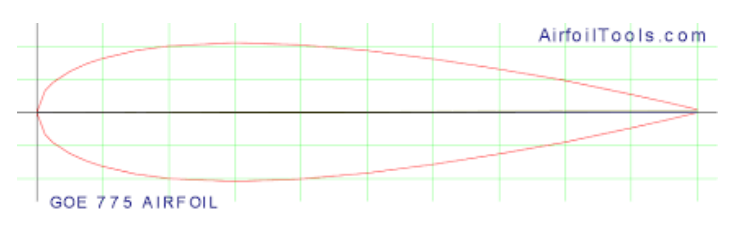

(d) NACA0021

Figure 5 Blade Profiles (Source:airfoiltools.com)

NACA0012 has a maximum camber $0 \%$ at $0 \%$ chord with maximum thickness $12 \%$ at $30 \%$ of chord. NACA0015 has a maximum camber $0 \%$ at $0 \%$ chord with maximum thickness $15 \%$ at $30 \%$ of chord. NACA0018 has a maximum camber $0 \%$ at $0 \%$ chord with maximum thickness $18 \%$ at $30 \%$ of chord. NACA0021 has a maximum camber $0 \%$ at $0 \%$ chord with maximum thickness $21 \%$ at $30 \%$ of chord.

In this study, we consider the effect of mainstream wind velocity on different blade profiles. The velocities at which the turbines are tested are $3,6.5$ and $10 \mathrm{~m} / \mathrm{s}$. These velocities are chosen to study the wind turbine over a range of wind velocities by staying within the limits of average wind speeds.

Analysis of VAWT using ANSYS: 
Mesh Details: The model is uploaded into ANSYS and the mesh is applied. The type of mesh applied is the Iso-surface mesh. The meshed model is then cleaned up for proper analysis. The cleanup involves making sure that the nodes are clean and to ensure skewness of the mesh is within appropriate limits. The mesh is set to have a minimum element size of $0.5 \mathrm{~mm}$ up to a maximum element size of $10 \mathrm{~mm}$. The elements present in critical areas of analysis (blade walls) have a smaller element size to give a more accurate result and the elements present in non-critical areas have a larger element size. A cylindrical domain is created for analysis with a diameter of $2000 \mathrm{~mm}$ and a height of $1400 \mathrm{~mm}$. The domain is set to have a fluid medium of air with a density of $1.225 \mathrm{~kg} / \mathrm{m}^{3}$ and a viscosity of $1.802 \times 10^{-5} \mathrm{~kg} / \mathrm{m}$-s. The surfaces of interaction on the domain are Inlet, Outlet, wall (top and bottom) and the Blade-wall. The turbulence model used in this study is the $\kappa-\varepsilon$ model. This model is appropriate for analysis of wind turbines. The gauge pressure of the domain is set at $0 \mathrm{~atm}$. Boundary conditions are then applied to the domain before analysis. The inlet is set to receive velocity as input and the mainstream wind velocity values are applied here. The blade-wall is set to measure pressure distribution across its surface. The outlet is set to gauge pressure (=0 atm) so as to measure the right value of pressure at the blade-wall. The wall (top and bottom) does not have any boundary conditions.

Calculation of Power Coefficient:

Formula used for power coefficient calculation:

Power coefficient $=c_{p}=P /\left(0.5 * A * U_{0}{ }^{3} * \rho\right)$ Equation[1]

where

- $\mathrm{P}=$ Pressure on surface of blade $(\mathrm{Pa})$

- $\mathrm{A}=$ Swept Area $=3768000 \mathrm{~mm}^{2}\left(=\pi^{*} \mathrm{D} * \mathrm{H}=3.14 * 2000 \mathrm{~mm} * 1200 \mathrm{~mm}\right)$

- $\mathrm{U}_{\mathrm{o}}=$ Mainstream wind velocity

- $\rho=$ Air density $=1.225 \mathrm{~kg} / \mathrm{m}^{3}$ 


\section{Calculation Procedure:}

Upon analysis, the values of average pressure distribution are determined for each configuration. These values are fed into the formula for power coefficient as in Equation (1). Once the power coefficient for each configuration is determined, they are tabulated and compared amongst the configurations through charts.

\section{RESULTS AND DISCUSSION}

Values of Power Coefficient obtained:

The values obtained in calculation of power coefficient are listed below.

Table 1 Blade profile - NACA0012

\begin{tabular}{|c|c|c|c|}
\hline $\begin{array}{c}\text { Pressure P } \\
(\mathrm{Pa})\end{array}$ & $\begin{array}{c}\text { Blade Pitch angle } \\
\beta\end{array}$ & $\begin{array}{c}\text { Mainstream wind } \\
\text { velocity } \mathrm{U}_{0} \\
(\mathrm{~m} / \mathrm{s})\end{array}$ & $\begin{array}{c}\text { Power coefficient } \\
\mathrm{c}_{\mathrm{p}}\end{array}$ \\
\hline 4.430772 & 0 & 3 & 0.01777 \\
\hline 3.10086 & 2 & 3 & 0.01244 \\
\hline 3.889698 & -2 & 3 & 0.0156 \\
\hline 36.81569 & 0 & 6.5 & 0.01452 \\
\hline 10.8605 & 2 & 6.5 & 0.00428 \\
\hline 39.188 & -2 & 6.5 & 0.01545 \\
\hline 90.79291 & 0 & 10 & 0.03934 \\
\hline 25.0131 & 2 & 10 & 0.01008 \\
\hline 93.05592 & -2 & 10 & \\
\hline
\end{tabular}


Table 2 Blade profile - NACA0015

\begin{tabular}{|c|c|c|c|}
\hline $\begin{array}{c}\text { Pressure } \mathrm{P} \\
(\mathrm{Pa})\end{array}$ & $\begin{array}{c}\text { Blade Pitch angle } \\
\beta\end{array}$ & $\begin{array}{c}\text { Mainstream wind } \\
\text { velocity } \mathrm{U}_{0} \\
(\mathrm{~m} / \mathrm{s})\end{array}$ & $\begin{array}{c}\text { Power coefficient } \\
\mathrm{c}_{\mathrm{p}}\end{array}$ \\
\hline 0.05889 & 0 & 3 & 0.00024 \\
\hline 0.52509 & 2 & 3 & 0.00211 \\
\hline 0.25526 & -2 & 3 & 0.00102 \\
\hline 23.2126 & 0 & 6.5 & 0.00915 \\
\hline 4.9163 & 2 & 6.5 & 0.00194 \\
\hline 21.65403 & -2 & 6.5 & 0.00854 \\
\hline 55.21815 & 0 & 10 & 0.00598 \\
\hline 19.442 & 2 & 10 & 0.00211 \\
\hline 0 & -2 & 10 & 0 \\
\hline
\end{tabular}

Table 3 Blade profile - NACA0018

\begin{tabular}{|c|c|c|c|}
\hline $\begin{array}{c}\text { Pressure } \mathrm{P} \\
(\mathrm{Pa})\end{array}$ & $\begin{array}{c}\text { Blade Pitch angle } \\
\beta\end{array}$ & $\begin{array}{c}\text { Mainstream wind } \\
\text { velocity } \mathrm{U}_{0} \\
(\mathrm{~m} / \mathrm{s})\end{array}$ & $\begin{array}{c}\text { Power coefficient } \\
\mathrm{c}_{\mathrm{p}}\end{array}$ \\
\hline 1.04224 & 0 & 3 & 0.00418 \\
\hline 2.31388 & 2 & 3 & 0.00928 \\
\hline 1.21758 & -2 & 3 & 0.00488 \\
\hline 12.56723 & 0 & 6.5 & 0.00496 \\
\hline 12.99199 & 2 & 6.5 & 0.00512 \\
\hline 16.97971 & -2 & 6.5 & 0.00669 \\
\hline 28.90908 & 0 & 10 & 0.00313 \\
\hline 30.32119 & 2 & 10 & 0.00328 \\
\hline 37.85962 & -2 & 10 & 0.0041 \\
\hline
\end{tabular}


Table 4 Blade profile - NACA0021

\begin{tabular}{|c|c|c|c|}
\hline $\begin{array}{c}\text { Pressure } \mathrm{P} \\
(\mathrm{Pa})\end{array}$ & $\begin{array}{c}\text { Blade Pitch angle } \\
\beta\end{array}$ & $\begin{array}{c}\text { Mainstream wind } \\
\text { velocity } \mathrm{U}_{0} \\
(\mathrm{~m} / \mathrm{s})\end{array}$ & $\begin{array}{c}\text { Power coefficient } \\
\mathrm{c}_{\mathrm{p}}\end{array}$ \\
\hline 1.57835 & 0 & 3 & 0.00633 \\
\hline 1.53793 & 2 & 3 & 0.00617 \\
\hline 2.96808 & -2 & 3 & 0.0119 \\
\hline 14.33326 & 0 & 6.5 & 0.00565 \\
\hline 13.22054 & 2 & 6.5 & 0.00521 \\
\hline 9.448428 & -2 & 6.5 & 0.00373 \\
\hline 33.44459 & 0 & 10 & 0.00362 \\
\hline 26.50722 & 2 & 10 & 0.00287 \\
\hline 19.46255 & -2 & 10 & 0 \\
\hline
\end{tabular}

Comparison of Blade Profiles:

The following charts (Figs.6-9) show the variation of power coefficient with respect to

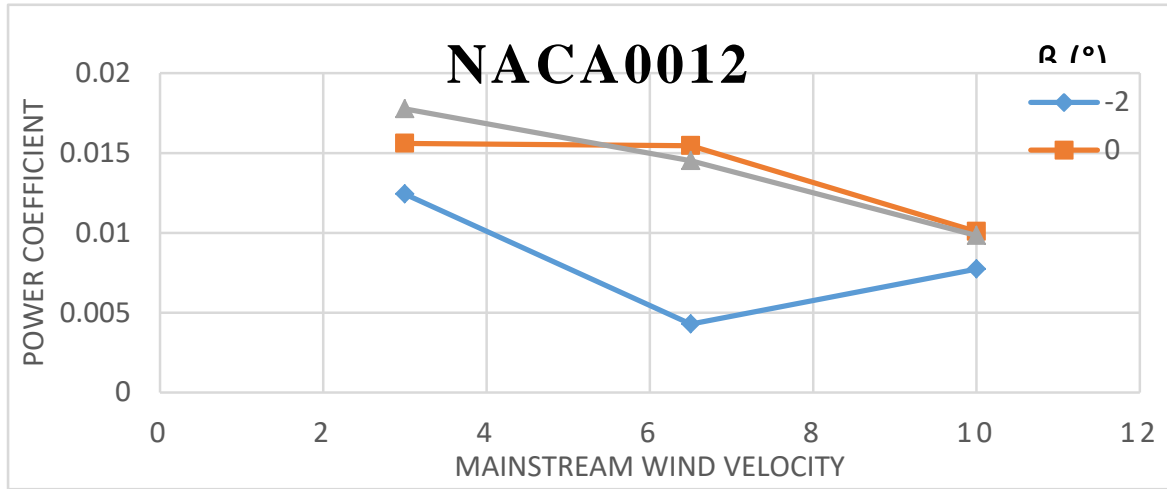

mainstream wind velocity and blade pitch angle for every blade profile taken in study.

Figure 6 Blade profile -NACA0012 - $\mathrm{U}_{0}$ vs. $\mathrm{C}_{\mathrm{p}}$

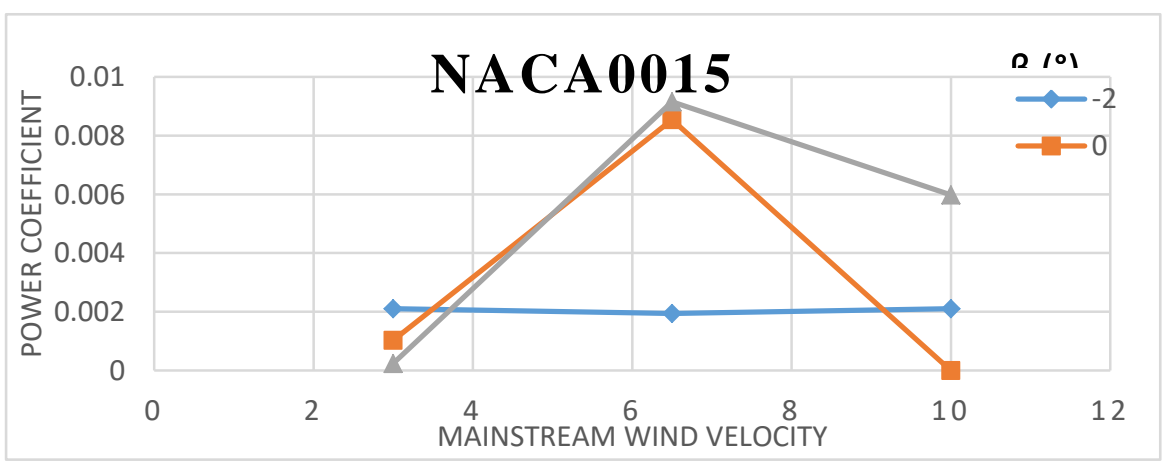


Figure 7 Blade profile -NACA0015 - $\mathrm{U}_{0}$ vs. $\mathrm{C}_{\mathrm{p}}$

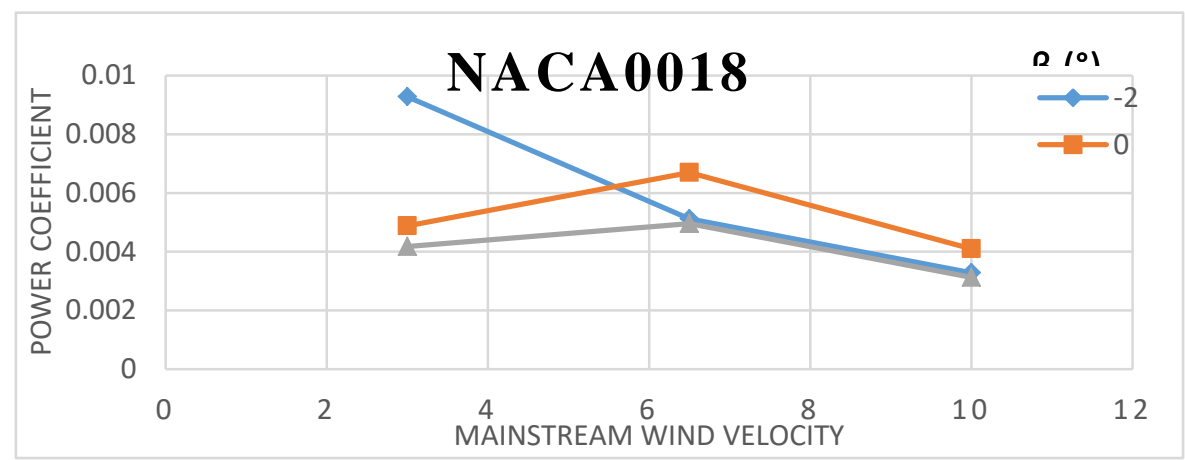

Figure 8 Blade profile -NACA0018 - $\mathrm{U}_{0}$ vs. $\mathrm{C}_{\mathrm{p}}$

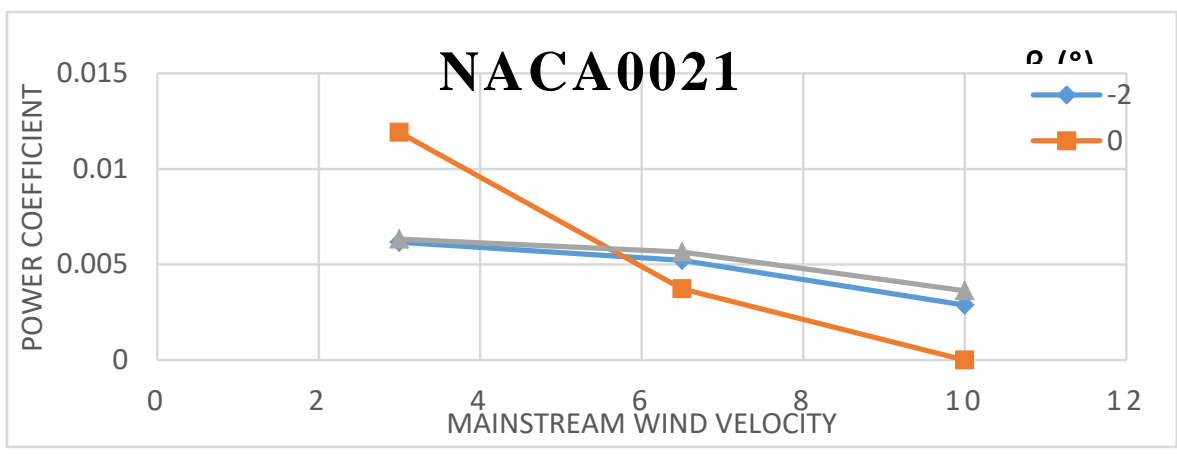

Figure 9 Blade profile -NACA0021 - $\mathrm{U}_{0}$ vs. $\mathrm{C}_{\mathrm{p}}$

The study has been done for all configurations suggested.

\section{Discussion:}

Comparing between wind blade profiles for the same wind velocity, it is found that NACA0012 holds a clear advantage over NACA0015, NACA0018 and NACA0021 across the range of wind velocity. However, it is seen that the power coefficient tends to decrease with an increase in blade pitch angle for the same velocity. There is also a decrease in power coefficient across wind velocity range for the same pitch angle. NACA0015 performs better than NACA0018 and NACA0021 with a $0^{\circ}$ pitch angle at intermediate and high velocities 
while giving poor results at low velocities. However, it gives almost negligible results with a $2^{\circ}$ pitch angle. It is found to cancel out completely at high speeds when it has a $-2^{\circ}$ pitch angle. NACA0018 performs well at the extremes i.e. at low and high velocities better than at intermediate velocities. For NACA0021, even though the power coefficient values obtained are low, they are consistently obtained across all configurations of the wind turbine.

\section{CONCLUSION}

The following conclusions can be derived from the study:

Blade profile NACA0012 is the best for producing a good power coefficient. One can say that it is the favorable candidate in cases of high energy requirement, especially in areas having low to intermediate wind speeds. The blade profile consistent in giving results is found to be NACA0021. It is useful in areas where power requirements are low but consistent. This is especially in areas where wind speeds range from low to high. NACA0015 is useful as a blade profile for VAWTs only at a pitch angle of $0^{\circ}$ and at intermediate and high velocities while providing very low power coefficients at lower velocities. NACA0018 blade profile is especially useful in areas where there are extreme winds, either low or high. All configurations deemed useful are productive only when they are connected in series with similar wind turbines for an application. Siting of a set of wind turbines can seem extensive, but this problem can be solved by considering the idea of implementing wind trees i.e. an artificial tree-like structure which has multiple wind turbines on its 'branches'. This multiplicity makes room for installation of more turbines and also renders a height advantage. 


\section{REFERENCES:}

Kumar, R., Raahemifar, K., \& Fung, A. S. (2018). A critical review of vertical axis wind turbines for urban applications. Renewable and Sustainable Energy Reviews, 89, 281-291.

Pagnini, L., Piccardo, G., \&Repetto, M. P. (2018). Full scale behavior of a small size vertical axis wind turbine. Renewable energy, 127, 41-55.

Jafari, M., Razavi, A., \&Mirhosseini, M. (2018). Effect of airfoil profile on aerodynamic performance and economic assessment of H-rotor vertical axis wind turbines. Energy, 165, 792-810.

Difuntorum, J. K., \&Danao, L. A. M. (2019). Improving VAWT performance through parametric studies of rotor design configurations using computational fluid dynamics. Proceedings of the Institution of Mechanical Engineers, Part A: Journal of Power and Energy, 233(4), 489-509.

Hashem, I., \& Mohamed, M. H. (2018). Aerodynamic performance enhancements of Hrotor Darrieus wind turbine. Energy, 142, 531-545.

Islam, M., Ting, D. S., \&Fartaj, A. (2007). Desirable airfoil features for smallercapacity straight-bladed VAWT. Wind Engineering, 31(3), 165-196. 